\title{
What does Corporal Punishment in Schools Mean? : Trend of Case Law
}

Hitoshi Miyahara

Faculty of Law, Toyo University

Follow this and additional works at: https://gensoken.toyo.ac.jp/japanese-society-and-culture

Part of the Constitutional Law Commons, and the Japanese Studies Commons

\section{Recommended Citation}

Miyahara, Hitoshi (2020) "What does Corporal Punishment in Schools Mean? : Trend of Case Law," Japanese Society and Culture: Vol. 2 , Article 3.

DOI: $10.52882 / 2434-1738-0203$

Available at: https://gensoken.toyo.ac.jp/japanese-society-and-culture/vol2/iss1/3

This Article is brought to you for free and open access by Institute of Social Sciences. It has been accepted for inclusion in Japanese Society and Culture by an authorized editor of Institute of Social Sciences. 


\title{
What does Corporal Punishment in Schools Mean? : Trend of Case Law
}

Hitoshi Miyahara *

\begin{abstract}
Since the Meiji era, school education statutes have consistently prohibited corporal punishment. However, corporal punishment never disappeared from schools. We have to consider the reasons why teachers are unable to avoid them. The Supreme Court of Japan has ruled that corporal punishment is illegal, but that teachers could adopt certain forms of "physical contact" in the course of instruction. Their conduct becomes illegal only when they abuse their power. Case law indicates that a decision on whether they abused it is made after considering all circumstances, for example the necessity to use force, purpose of instruction, and method of discipline.
\end{abstract}

Keywords: Corporal Punishment in Sports Trainning, Physical Contact, Discipline, Discretion of Teachers, Bodily Injury, Inquiry of Teachers,

Introduction

Article 11 of Gakkou-Kyouiku-Hou 学校教育法 (the School Education Law) allows the principal and teachers of a school to discipline students when necessary, but they are prohibited from inflicting corporal punishment. Nevertheless, corporal punishment is still prevalent in schools, and it has sometimes triggered student suicides. Why does this form of punishment persist despite the ban? It is easy to criticize teachers for administering corporal punishment, but we have to consider the reasons why they are unable to avoid them.

Young students experience a lot of emotional changes during adolescence. They have different characteristics and study interests, and come from diverse backgrounds. As a result, a teacher faces significant challenges in undertaking the instruction, guidance, and administration of students in his/ her class. There are some students who disobey their teachers' instructions and openly defy them. If no action is taken, it could result in Gakkyu Houkai 学級崩壊 (classroom disintegration). To prevent such an outcome, corporal punishment could be inflicted. However, it is doubtful whether corporal punishment is effective in dealing with such behavior ${ }^{1}$.

The Supreme Court of Japan has ruled that corporal punishment is illegal, but that teachers could adopt certain forms of "physical contact" in the course of instruction. We have to determine what corporal

\footnotetext{
※ Professor, Faculty of Law, Toyo University, Constitutional Law

1 Scholars are divided on this issue. On the one hand, use of some force may reveal students' dauntless attitude and teachers' enthusiasm. See Yoshitaka Ban \& Yoshiaki Yoshino, Case Comment, 323 Hannrei-Chihoujiti 8 (2010). On the other hand, compulsion and violence are incompatible with the fundamental objective of the School Education Law. Only reprimands and admonitions should be permitted as disciplinary actions. See Tsuyoshi Yamayoshi, The Right of Discipline and Corporal Punishment: Tendency of Case Law, 27 Kikann-Kyoiku-Hou 108 (1983).
} 
punishment is and how it is different from the acceptable types of "physical contact" in the course of instruction. In this article, I will first introduce the statutes on school education and their administrative interpretations, and then analyze the related case law.

Chapter I - Written Laws and Administrative Interpretation

Statutes and Administrative Legislation

Before the Second World War, corporal punishment had been prohibited, at least, in the text of the law on education. For the first time, Kyouiku-Rei 教育令 (the Administrative Legislation on Education of 1879) specified that any form of corporal punishment (beating, tying up, etc.) was prohibited in schools.

Second, Dainiji-Shougakkou-Rei 第二次小学校令 (the second Administrative Legislation on Elementary School Education of 1890) banned school principals and teachers from inflicting corporal punishment.

Third, Daisanji-Shougakkou-Rei 第三次小学校令 (the third Administrative Legislation on Elementary School Education of 1897) specified that although school principals and teachers can discipline students when necessary, they are prohibited from inflicting corporal punishment. This legislation is similar to the School Education Law now in force.

\section{Administrative Interpretation of Legislation}

Administrative interpretations of education laws that came after the Second World War have explained what the term "corporal punishment" means. The Ministry of Justice (December 22, 1948) explained that corporal punishment included beating, kicking, and physical pain inflicted by requiring a student to remain in the same pose for a long time, such as making students kneel on the floor (Seiza 正座) or stand in a corner.

The Ministry of Justice (August 2, 1949) specified that teachers should ensure that students ate their meals and allow them to have a wash when they stay back for class after school hours. Moreover, they were prohibited from shutting latecomers out, and forcing students to confess to larceny in class.

However, the administrative interpretation of the laws changed in 2007. The Ministry of Education, Culture, Sports, Science and Technology (MEXT February 5, 2007) said that any decision on whether corporal punishment was unwarranted or justifiable should be made on a case-by-case basis after taking into consideration factors such as the age, health conditions, and the physical and mental development of the concerned students, as well as the place and mode of discipline ${ }^{2}$. Moreover, it is highly probable that students' violent behavior forced teachers to resort to such disciplinary action in an act of self-defense ${ }^{3}$.

This change in interpretation may have come to prevent classroom disintegration, a situation that teachers have to deal with dauntlessly. Teachers could adopt certain types of physical contact during instruction in order to maintain order in class. However, the language "prohibiting the infliction of corporal punishment" remains in the School Education Law, making it necessary to distinguish corporal

2 This administrative interpretation narrows down the scope of corporal punishment although it is expressly prohibited. See Yasusaburou Hoshino, Case Comment, 41 Kikann-Kyouiku-Hou 146(1981).

3 When students resort to violence against teachers, any retaliation does not constitute corporal punishment, but is considered to be legal conduct and an act of self-defense. See Atsuko Tohyama, Legal System of Discipline and Prohibited Corporal Punishment in Schools, 47 Kikan-Kyoiku-Hou 21 (1983). To decide whether teachers' conduct was carried out in self-defense or not, the action must be considered from the perspective of not only criminal or tort law, but also educational instructions. See Hide Yamagishi, Violence in School and Corporal Punishment, 47 KikanKyouiku-Hou 31 (1983). 
punishment (illegal) from certain types of physical contact in instruction (legal). However, that is not so easy. We will examine the trend of court decisions on this issue by analyzing case law.

Chapter II - Case Law

Case 1: Discretion of teachers

The Court of Appeals of Tokyo, 1007 Hanrei -Jiho 133 (April 1, 1981)

This case, which had a great impact on the case law, explained in detail the extent of physical contact allowed during the course of instruction. In the case, (A) (the accused, a teacher at a middle high school) tapped the student (B) on his head with her lightly clenched fist, because he played pranks during the physical strength test. He died eight days later, and she was accused of assault (the cause-and-effect relationship between his death and her tap was not established). The Court decided that her conduct came under Article 208 of the Criminal Code (assault), but she was not guilty when her conduct was considered under Article 35 of the Criminal Code (i.e., when she conducts a lawful business, she is not guilty even if her conduct comes under the criminal code).

The issue at hand was whether her conduct came under the disciplinary measures provided in Article 11 of the School Education Law. The Court explained that disciplinary measures are one of the ways of non-curricular guidance that teachers can adopt with great discretion. Because teachers are well aware of their students' character, conduct, merits, and demerits, they are well-placed to decide whether or not a student is to be disciplined, and which measure needs to be adopted. Her tapping on (B)'s head was a small infringement on his body, almost the same as an oral reprimand ${ }^{4}$. As a result, it was within the discretion of discipline, and justified under Article 35 of the Criminal Code.

\section{Case 2: Bodily Injury (1)}

The District Court of Osaka, 1494 Hanrei-Jiho 130 (September 3, 1993)

When students are actually injured by teachers' disciplinary action, courts often consider their conduct to be beyond their discretion of discipline and declare it illegal. Lecturer (A) taught practical drawing. He instructed his class of students to submit their copies regardless of whether they were completed or not. However, student (B) continued to work on his drawing even though (A) repeatedly called on him to submit it. Subsequently, (A) hit him with the attendance list (millboard, $27 \mathrm{~cm} \times 13 \mathrm{~cm}$ ) several times, causing (B)'s eardrum to split. The Court acknowledged the damage suffered by (B). It noted that (A)'s conduct had an educational purpose, and was done from necessity because (B) ignored his instruction, but inflicting injury on the student, for which he needed medical treatment for two weeks, constituted illegal conduct.

Teachers have the discretion to decide whether or not students need disciplining, and to select the mode of disciplinary action ${ }^{5}$. Their conduct is considered to be legal when they are within their

\footnotetext{
4 A teacher is within his/her legal authority when his/her physical contact with a student is accompanying oral instruction. See Kazuo Kitamura, Case Comment, 1398 JURIST 69 (2010).

5 Because corporal punishment may cause physical infringement, standards should be as objective as possible. Atsuko Tohyama, Legal System of Discipline and Prohibited Corporal Punishment in schools, 47 Kikan-Kyoiku-Hou 21 (1983)
} 
discretion, even if the conduct comes under criminal or civil code (tort).

Case 3: Bodily Injury (2)

The District Court of Urawa (Saitama), 1160 Hanrei-Jihou 135 (February 22, 1985)

In this case, the Court did not provide relief to a student even though his teacher hit him with the attendance list. Student (A) was usually restless and had a bad attitude in the classroom. One morning, he was not in his seat for morning self-practice, so his teacher (B) hit him with the attendance list (paperboard $35.5 \mathrm{~cm} \times 20 \mathrm{~cm}$ ), but did not injure him physically. The court rejected the damage.

The court decided that the case had to be judged from a larger perspective that took into account a variety of factors, including the student's character, his age and health conditions, and the fact that the teacher did not cause him bodily harm. (B)'s action was therefore similar to oral discipline, and within the sphere of his authority.

(A) usually took a defiant attitude toward teachers, broke the rule of "taking a chair" repeatedly, and was elected a juvenile gang vice-leader in the school. Based on all these facts, the court decided that (B)'s conduct was the same as oral discipline, and therefore legal.

\section{Case 4: Inquiry (1)}

The District Court of Tokyo, 1051 Hanrei-Jihou 114 (1982)

Before disciplining students over any alleged misbehavior, teachers often question students about the allegations and occasionally administer corporal punishment. A resident living near an elementary school complained that a schoolboy (A) had broken the window of his residence with a pachinko ball, and that his admonishments had been in vain. Teacher (B) interviewed (A), who admitted to having the ball, but denied throwing it and breaking the window. Angered by the answer, (B) said to (A) repeatedly that it was only fair for him to be hit if he had committed the misdeed, asked (A) why he lied about the incident, and warned him that he would be blamed whenever there was any such incident in the future. Subsequently, (A) admitted to having broken the window. He tried to commit suicide by jumping from a height, suffering serious injuries that required eight months of treatment. The court dismissed the request for damages, saying: "We do not think that inquiry by teachers is illegal, but the use of improper language is not befitting of teachers."

In this case, the court found that the teacher's language was not appropriate, but the inquiry was not illegal, and explained the rationale for their judgment. (A) was a sixth-grader at the elementary school who was scheduled to graduate from the school in not more than one month. He caused damages to a neighbor of the school, but what was worse was that he ran off when admonished, which was a serious affair and needed to be resolved promptly. This explanation seems to be almost persuasive, but only with respect to the motive of the inquiry. The court should have explained more clearly whether the inquiry was carried out appropriately or not. 
Case 5: Inquiry (2)

The District Court of Fukuoka, 1605 Hanrei-Jihou 97 (March 19, 1996)

(A), a teacher at a middle high school, invited several students from his class for a barbeque party at his house, where he admonished them over their bad behavior and asked them to correct their conduct. Student (B) was among the students invited to the party. A few days after the party, they were taken into custody by police on suspicion of extortion. The principal and (A) apologized to the victims, but two days later, (B) again extorted money from a student of another middle high school. (A) called (B) to the school and asked him whether he had committed the misdeed or not, but (B) failed to acknowledge it.

(A) thought that it was necessary for (B) to seriously reflect on what he had done. He took the student on a 20-minute drive to the seashore, where (A) dug a hole in the ground and buried (B) up to his neck so that he could not move. After 15 minutes, (B) admitted to the misdeed, and was released from the hole. (B) sued for damages, which the court granted.

The court decided that (A) had disciplined (B) beyond the limit of his discretion. (B) failed to admit to his extortion activities when asked orally. Although (A) ensured that (B) was not injured when buried, (B) suffered great mental anguish and humiliation because of (A)'s action. Even if the intention was right, the conduct of (A) was horrifying and illegal, the court found. I believe that this decision was reasonable. However, I would like to raise several points.

First, the court accepted that burying (B) under the ground was a disciplinary action, but the act was essentially an inquiry for the purpose of knowing what had happened so that the teacher could decide whether discipline was needed and what kind of disciplinary action was suitable. As such, we have to distinguish discipline from inquiry.

Teachers interrogate students, who always fail to follow their instructions, in order to know the truth. Teachers, especially those encountering serious trouble from students, are often under great pressure. However, a confession that is not voluntary is not valid oral evidence under Article 38, Section 2 of the Constitution, which is applied to criminal procedure, although not directly to administrative process. Confession derived by force cannot be evidence because violence or torture distorts the contents of oral evidence. Teachers who interview students have to remember this detail.

Second, is it necessary for teachers to tackle delinquent behaviors that are unrelated to academics and happen outside of the school? To what extent are they responsible for the conduct of their students? It would be a burden if they are required to deal with, for instance, street fights between students of several schools.

Third, can teachers not take any action at all, which causes physical pain or humiliation to students? I believe that it is a matter of degree and depends on good faith, or the confidence that teachers are only striving to make their students better.

Case 6: Corporal Punishment in Sports Training (1)

The District Court of Urawa (Saitama), 1504 Hanrei-Jihou 106 (November 24, 1993)

Sometimes corporal punishment is inflicted during sports training. Teacher (A) was a supervisor of a volleyball club at a middle high school. After the first game, (A) called students of his team around him, 
let them all reflect on their play, and then slapped them all. Student (B), who was slapped, reeled and then hit his head against a pillar. Because he suffered long-term damage, he took the matter to court. The court granted his request for damages.

(A) explained that the purpose of the slapping was to put more fight in them, but the Court decided that his action essentially portrayed his anxiety over the possibility that they would lose the next game. There were no educational considerations to justify the slapping.

Corporal punishment is often inflicted in extracurricular activities like sports. Instructors are possibly apprehensive that students would not practice hard and would fail to get good results. They could be possessed by the idea that the students' attitude is due to their mental weakness and laziness, which could be overcome if they suffered physical pains. However, this idea and its execution have occasionally yielded tragic outcomes.

Case 7: Corporal Punishment in Sports Training (2)

The District Court of Gifu, 1487 Hanrei-Jihou 83 (September 6, 1993)

Student (A), a javelin thrower with the track-and-field club of a high school, won a prefectural javelin tournament and took part in the National Athletics Meet. The club supervisor (B), who had been training students, often used to slap them, and hit their head and hips with a javelin used for training (made of bamboo). He abused girls with remarks like "you should quit the club," "you are of no use," and "you are ugly."

(B) had hit and abused (A) for two years. She had been hit several times with a javelin used for game (made of duralumin), and had a bruise around her eyes. She was often called "lazybones," "a dimwit," and "ugly." (B) admonished her for blindly following instructions when she did not perform well. One day in March, when she failed in her exams (although she wrote the annual make-up examination), (B) rebuked her severely for one hour and said that he would never let her practice again. Next morning, she hung herself in her room.

The court decided that because the activities at a school club are part of the academic program, Article 11 of the School Education Law is applicable to them. Therefore, if teachers abuse their discretion of discipline, their actions are illegal. Although some students acknowledge the need for a level of stringency, this does not include hazing, insult, or training without any plans and considerations. There can be no mutual understanding between teachers and students regarding students' acceptance of such actions.

Busu (ブス ), which usually means “you are an ugly girl," was an insult to the appearance, and not related to the ability or skill of athletes at all. We have to understand the expression not as a single abuse, but as a chain of abuses, which added to the physical infliction.

How unfortunate that a 17-year-old girl with exceptional talent in sports put an end to her own life! A supervisor cannot be under the illusion that he owns his students, and can do anything to them. He has to remember that they are different from him, and have an identity of their own. To prevent abuse and violence under the guise of training, it is necessary for fellow teachers, educational boards, and parents to be concerned about students' problems and to communicate with each other. 
Case 8: Limit of Physical Contact

The Supreme Court of Japan, 62 (4) Min-Shu 904 (April 28, 2009)

I have pointed out some cases where teachers were clearly at fault. However, does this mean that they cannot resort to corporal punishment under any circumstances? What can they do if students do not obey their oral instructions? Is corporal punishment or physical contact by any means prohibited? Remember that the administrative interpretation of the School Education Law indicated that teachers are prohibited from administering corporal punishment, but their conduct is judged based on the circumstances. Does it mean that teachers may use some kind of physical contact with students in the course of instruction? The following case reveals the limit of physical force allowed under law.

Pupil (A) (130 cm tall) was a second grader at an elementary school, and followed his teacher (B) (167 $\mathrm{cm}$ tall) around when (B) was pacifying a first grader who was having trouble operating the computer. (B) asked (A) not to follow him. (A) took off, but playfully kicked some girls who were coming along. (B) then admonished (A) and asked him to stop it. However, (A) kicked at (B)'s hips twice and ran away, but (B) followed and caught him. (B) pinned him to a wall, seized his lapels, and scolded him severely saying "you must never do it." That night (A) screamed in his sleep. His appetite decreased and he was not able to attend school, but he got better after hospital care.

The Court decided that (B)'s physical contact with (A) was aimed at instructing (B), but it also caused him physical pain. (B) was angry at having been kicked, but his conduct and remarks might be inappropriate for an educator. However, his conduct was found to be within the discretion of instruction, which is permitted under Article 11 of the School Education Law, when the purpose, means, and length of time of his conduct were taken into consideration.

Teacher (B) not only admonished (A) orally, but also exercised physical force (pinning (A) to the wall and seizing his lapels). Does (B)'s action constitute corporal punishment? The Court may refer to the administrative interpretation of laws (2007) to decide whether an action amounts to corporal punishment or not, after considering all circumstances, such as age, health conditions, and the physical and mental development of the student, on a case-by-case basis. Teachers can use force in response to violence by students as an act of self-defense or an act of necessity. In this case, (A) kicked the girls passing by as well as the teacher. (B) exercised force in order to make (A) understand that his behavior was not acceptable, and that a teacher could retaliate if a student exhibited violent behavior. The court may emphasize that (B) did not beat, slap, or kick (A), but had only pinned him to the wall and rebuked him. Certainly (A) was seized with fear, but (B)'s conduct was found to be within the educational discretion after considering all circumstances 6 .

\section{Conclusion}

Since the Meiji era, school education statutes have consistently prohibited corporal punishment. However, corporal punishment never disappeared from schools. The recent administrative interpretation of education laws and the precedent set by case law may help distinguish corporal punishment, which is

\footnotetext{
6 Certain types of force may be effective to call students' attention to instruction and to make them reflect on their actions, but it is difficult to settle on the matter of degree. See Kunihiro Ohnuma, Corporate Punishment and Criminal Liability of Teachers, LOOKING OUT OVER 21 CENTURY (Law Meeting of Seijyo University, Shinzansha, 1999$) 364$.
} 
illegal, from other types of force that can be used to discipline students. How can we distinguish these?

Teachers are permitted to use certain types of physical force within their discretion of discipline, and their conduct becomes illegal only when they abuse this power. Case law indicates that a decision on whether they abused it is made after considering all circumstances.

The most important things to be considered are the necessity to use force, purpose of instruction, and method of discipline. In addition, we have to understand the regular attitude of a student: whether he is defiant, follows instructions, or repeats illegal behavior. Furthermore, teachers have to remember that each student has a unique personality, and their task is to help improve it regardless of the situation. 